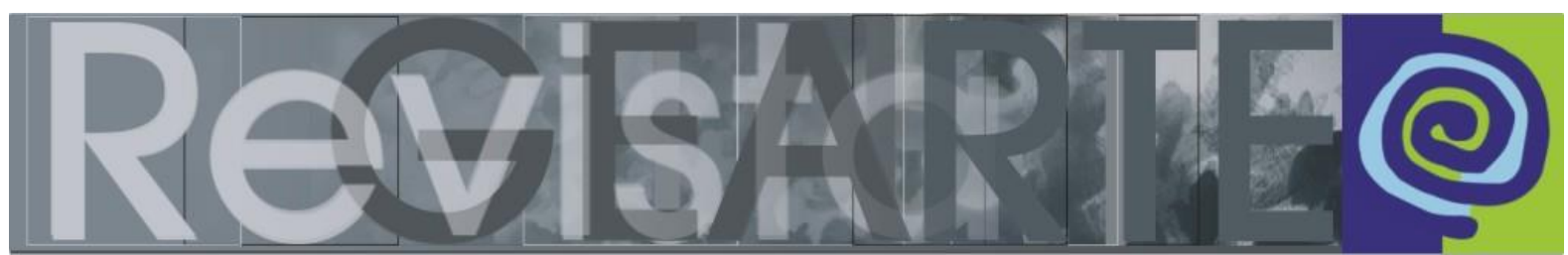

ISSN 2357-9854

\title{
Tecidos femininos: reflexões sobre um processo de criação artística
}

Maria Regina Johann (Universidade Regional do Noroeste do Estado do Rio Grande do Sul — UNIJUÍ, ljuí/RS, Brasil)

RESUMO - Tecidos femininos: reflexões sobre um processo de criação artística - Este trabalho é resultado de uma pesquisa em Artes Visuais na qual me apropriei de imagens que foram manipuladas, organizadas, digitalizadas e, algumas, interferidas com desenho e pintura. A materialização dessas manipulações resultou num conjunto de textos visuais a respeito dos quais faço uma reflexão, enfatizando o modo como se deu a pesquisa artística e o sentido pessoal a partir de uma experiência estética e autoformadora que desvelou memórias femininas.

PALAVRAS-CHAVE

Textos Visuais. Estética. Experiência.

ABSTRACT - Female cloths: reflections on a process of artistic creation - This work presents the result of a research in visual arts in wich I appropriated some pictures that were manipulated, organized, scanned and some of these pictures suffered interferences with drawing and painting. The materialization of this manipulations resulted in a group of visual texts, and about this I make a reflection, giving some emphasis to how works artistic research and personal sense from an aesthetic experience and "self forming" that unveiled womanly memories.

\section{KEYWORDS}

Visual Texts. Aesthetic. Experience.

Este texto apresenta um recorte de um conjunto de 100 trabalhos desenvolvidos com base em uma pesquisa artística em atelier, a qual reflete sobre a busca de uma ideia e sobre o processo que se dá a partir do momento em que algo nos acontece e permite um processo de pesquisa. Nessa reflexão trago a noção de experiência gadameriana e tematizo sua perspectiva autoformadora, uma vez que a experiência como experiência põe-nos diante do outro e, por isso, cria situações de deslocamentos e revalidações.

À época dessa pesquisa eu estava em busca de motivações para retomar meu processo de criação artística e, assim, interessei-me por aulas de atelier ${ }^{1}$, pois há algum tempo estava mais dedicada aos estudos teóricos sobre arte e seu ensino. Em

1 Em 2008 e 2009 frequentei aulas de atelier sob orientação de Rosana Berwanger Silva, artista, publicitária e professora de Artes Visuais. Nessas aulas fui desafiada a experimentar, relacionar, investigar materiais e ideias, ao mesmo tempo em que realizei reflexões acerca do trabalho, buscando ampliar a compreensão do que estava produzindo. 
vista de um tema ou ideia para produzir, meu dilema inicial foi: por onde começar ou recomeçar? O que experimentar diante de tantas possibilidades e materiais? Inicialmente tomei como referência o pensamento de Edith Derdyk (2001, p. 9), a qual menciona que "a linha de horizonte, sem ponto de chegada nem ponto de partida, sempre aporta e inicia sobre suas costas onduladas para, em qualquer instante, inscrever-se no tempo de um lugar". Essa ideia ilustra um pouco a forma como olhei para minha trajetória artística da época, buscando rever minhas criações, observando os procedimentos e a linguagem para, então, vislumbrar uma referência para recomeçar, ou seja, perspectivar uma "linha de horizonte".

Pensando sobre o que já havia realizado e observando as características de meu trabalho artístico, sobretudo do que gosto de fazer, percebi que tenho uma tendência à apropriação, à recontextualização de imagens e de objetos e que, em minhas pinturas, estava muito presente a colagem de tecidos, especialmente o tecido de Chitão. Diante dessa memória, sentia necessidade de uma questão/problema/ideia inicial, algo que possibilitasse uma ação para pensar sobre ela, ou seja, necessitava de um problema de ordem artística.

Retomando a leitura do texto de Derdik (2001), senti-me provocada pela ideia de que na linha de (meu) horizonte algo poderia emergir, aportar. Assim, entregueime a um tempo de olhar vagabundeante, dedicando-me a ver e desver as coisas mais óbvias, justamente para surpreender-me, abrindo-me para uma possível novidade. Permiti-me a estranhar meu entorno, a desnaturalizar meu olhar sobre as coisas.

Foi assim que encontrei nas páginas de um jornal uma imagem da fotógrafa Dorothea Lange, e foi amor à primeira vista. Esta fotografia me envolveu de tal maneira que, mesmo buscando outros materiais, era ela quem me seduzia para um processo. 


\section{Figura 1 - Dorothea Lange , Migrant Mother, 1936 (detalhe)}

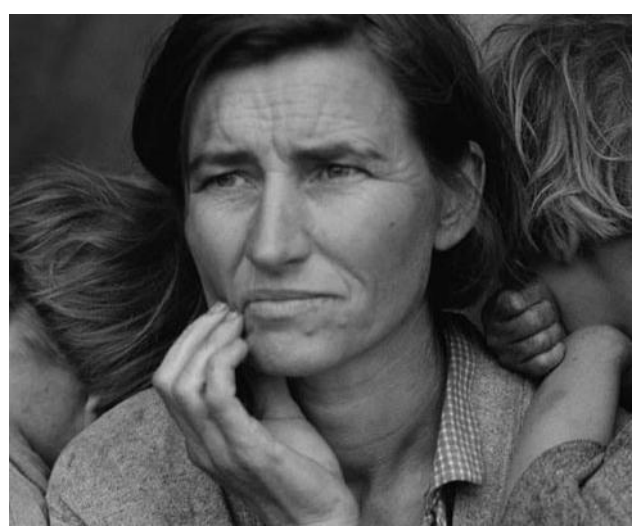

Fonte: <https://www.moma.org/collection/works/50989>.

Selecionei a imagem e também algumas palavras que faziam parte do texto no qual ela estava inserida. A partir daí tinha um horizonte, uma ideia; uma imagem e algumas palavras que provocavam pensamentos. Estava num estado de expectativa e excitação, pois, de certo modo, já tinha meu "problema" inicial de pesquisa: o que fazer com esta imagem e as palavras?

Mais uma vez Derdyk (2001) ajudou-me a compreender como um objeto/imagem pode desencadear um pensamento e uma ação, pois a imagem Migrant Mother suscitou uma série de possibilidades, produzindo em mim um pensamento crítico, visual e poético. A partir dessa fotografia, desencadeou-se todo um trabalho que foi se metamorfoseando ao se inter-relacionar com outros artefatos e imagens, tais como tecidos, figuras de obras artísticas e, ainda, pequenos objetos pessoais. Isso significa que uma ação e/ou objeto pode impulsionar uma pesquisa, na medida em que desencadeiam desejos, vontades, memórias, pois, conforme Derdyk (2001, p. 15),

[..] um corpo cria um pensamento, o corpo sustenta uma ação, o corpo vive ritmos, as (des) continuidades, as intensidades, as disjunções, as alternâncias. O pensamento borbulha no corpo, o corpo contrai com o pensamento, o pensamento gera um movimento, o movimento do corpo provoca as matérias do mundo.

Nesse sentido, a imagem escolhida, a princípio aleatoriamente, foi o "corpo" que gerou um movimento, impulsionando um trabalho artístico, pois, a partir dela, organizei um percurso de investigação no qual a busca deu-se em torno da exploração estética e de uma intenção poética que a imagem permitiu. Através dela, fui buscar 
outros elementos e materiais para a criação, encontrando um universo rico em possibilidades de construção que, articulados e mediados por alguns recursos tecnológicos (baixos), proporcionaram sobreposições, recortes, interferências, resultando em inúmeras composições. Estes textos visuais apresentam faces femininas, flores e palavras re/veladas - narrativas tecidas de memórias e histórias femininas.

Figura 2 - Feminina I

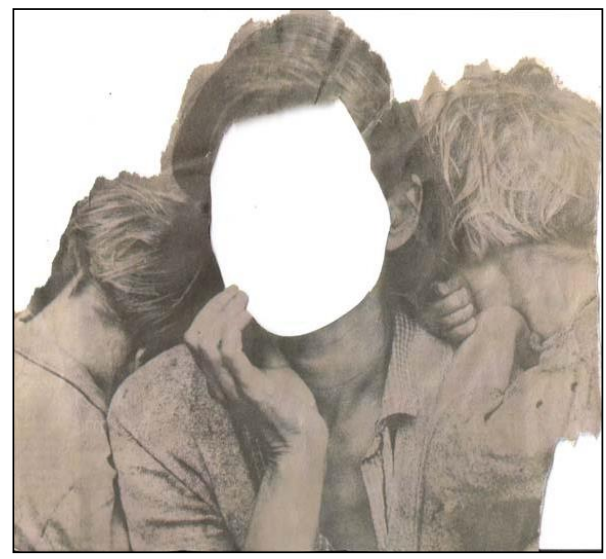

Fonte: acervo da autora.
Figura 3 - Feminina II

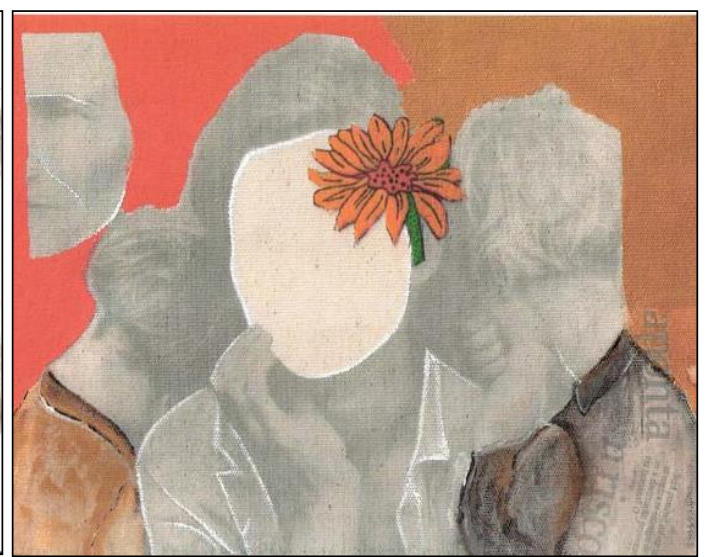

Fonte: acervo da autora.

Hoje, quando me debruço sobre estes textos visuais e observo as composições, percebo que a imagem da mulher com três crianças não foi escolhida sem a contribuição de minha própria história. Nela me vejo. Relembro e estabeleço relações com minha vida, com as imagens femininas que tenho na lembrança: marias, mães, santas, guerreiras, mulheres de corpos envelhecidos, faces cansadas, judiadas pela dureza da vida, mas de uma doçura comovente! As mulheres as quais me refiro eram as avós, as tias e, especialmente, a minha própria mãe. Mais tarde compreendi que essas mulheres foram fundamentais no meu desenvolvimento psíquico, cultural e afetivo. Relembrando cenas e momentos marcantes, como a morte de meu pai, percebo como minha vida se tramou nestas intersubjetividades, pois essas mulheres foram como muralhas protetoras e, ao mesmo tempo, marias cuidadoras me autorizando a viver. Já as palavras "risco" e "aponta" (retiradas do próprio texto 
jornalístico ${ }^{2}$, expressam uma dimensão frágil da existência e da condição humana, pois, como diz o poeta, "a vida é bala perdida, a morte é bala certeira" 3 .

Ao manipular a imagem Migrant Mother, retirando a face, conscientizo-me de que criei um vazio. Um campo neutro que, num primeiro momento, remete ao nada, um espaço infinito no qual couberam cenas e pensamentos. Espaço de onde emergem lembranças pessoais, de rostos conhecidos e familiares, mas, ao mesmo tempo, faces universais.

Descontextualizada, a imagem da mulher permite novas relações, um agora que pode ser e/ou conter eu, você ou elas. Assim, na medida em que fui experimentando várias possibilidades de articulações entre a imagem já recortada, desmembrada, deslocada, senti a necessidade de trazer outros elementos visuais para o trabalho. Apreciando livros de História da Arte Medieval deparei-me com imagens de Santas Bizantinas e Românicas que incorporei nas produções e, junto a elas, as flores de tecidos de Chita ${ }^{4}$. Parafraseando Hernández ${ }^{5}$, (2007) entendo que fui catando imagens, materiais e lembranças.

Figura 4 - Feminina III

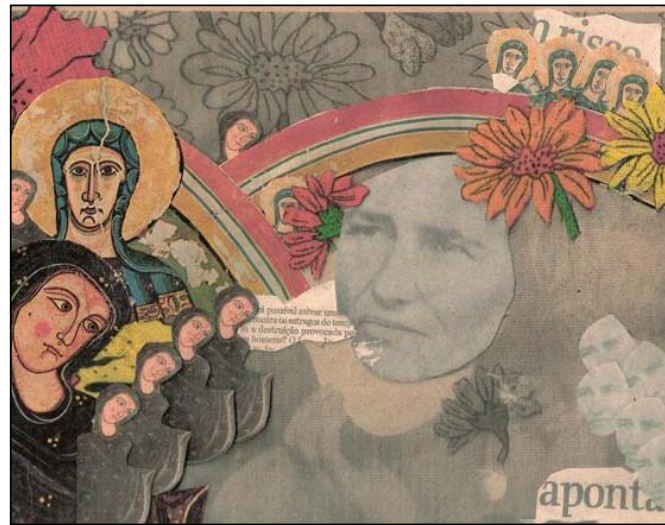

Fonte: acervo da autora.
Figura 5 - Feminina IV

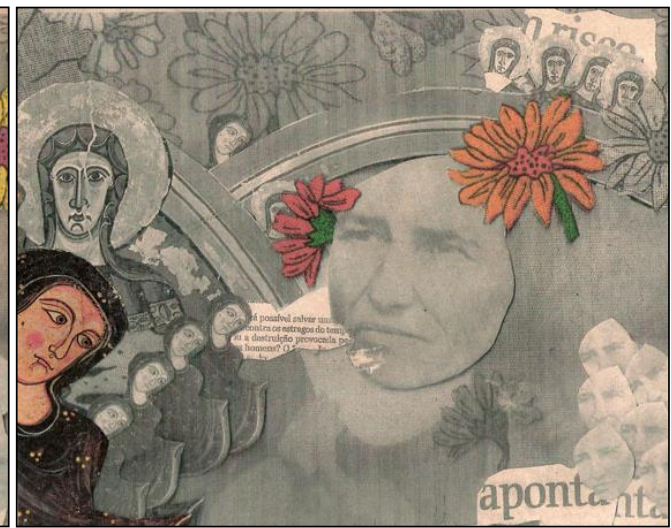

Fonte: acervo da autora.

2 Jornal impresso Zero Hora, edição do ano de 2008.

3 PIMENTEL, Airton. Charqueada. Interpretação do Grupo Os Tápes. In: Música popular do Sul. Disco vinil, v. 1, 1975.

4 Venho há tempos trabalhando com o tecido de chitão; dessa forma, incorporei as flores como elementos do feminino, materiais de trabalhos anteriores e como imagem das lembranças da infância.

5 Fernando Hernández utiliza o termo "catadores" como metáfora e como proposta para outra narrativa educacional, apresentado em seu livro Catadores da cultura visual: proposta para uma nova narrativa educacional (2007). 
À medida que fui estabelecendo relações entre as imagens, observei que elas se complementavam: a mulher e as santas, a santa e a mulher. Percebia, então, outra relação acontecendo, o profano e o sagrado, as marias e a Maria. Quando acrescentei a elas as flores de chita, novas relações ocorreram. Dessa vez de ordem estética, pois o tecido de chita é uma produção têxtil simples, de um material produzido há muitos anos e em grande escala, aqui no Brasil. Na minha infância, por exemplo, este tecido supria as necessidades de uma população com menos recursos financeiros e, também, com um gosto mais popular. Inúmeras foram as casas que frequentei quando criança, em que as divisórias internas eram feitas de cortinas de chita. Tomada por esta lembrança, fui entendendo um pouco o meu gosto (afetivo) por este tecido, imaginando quantas vezes devo ter contemplado as flores, as composições, as cores. Estas imagens devem ter ficado como lembranças afetivas, pois nas casas das amigas, das tias e avós brincávamos entre estes panos. Lembro que éramos felizes, uma vez que tínhamos o mundo todo para nós e o tempo infinito que a infância permite.

Figura 6 - Feminina V

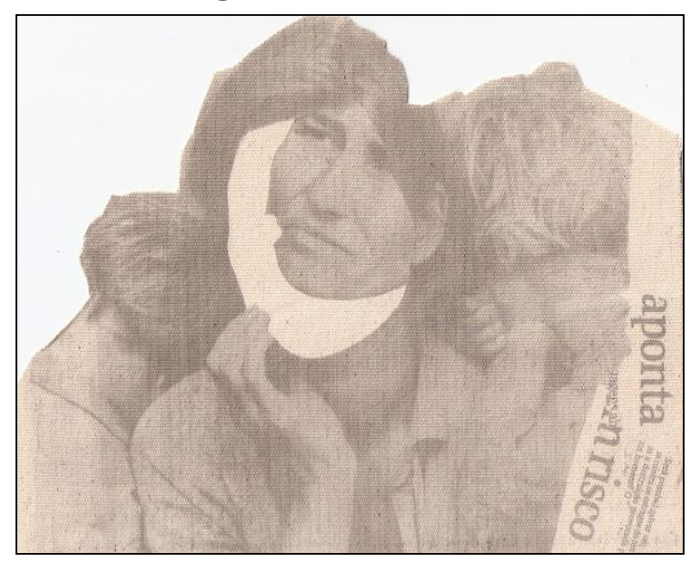

Fonte: acervo da autora.
Figura 7 - Feminina VI

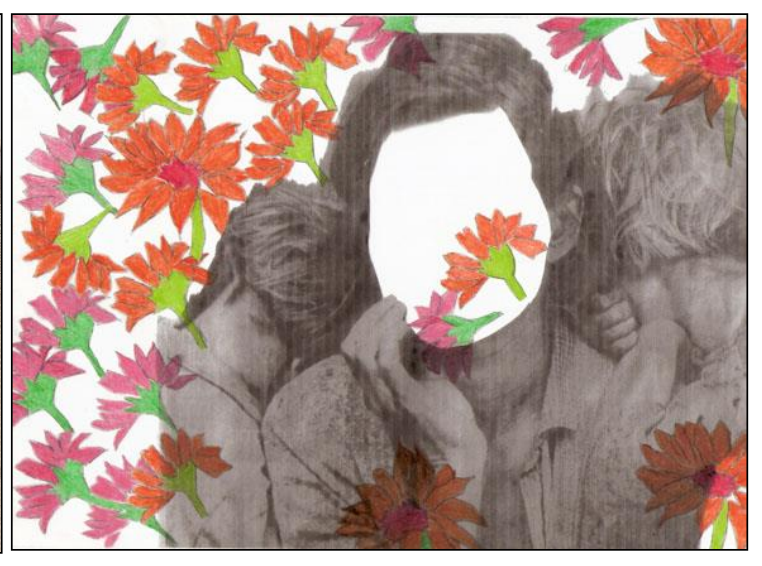

Fonte: acervo da autora.

Mas como estava desafiada a trabalhar com as imagens, também numa perspectiva de investigação plástica, elaborei composições em que os acasos não eram desprezados. Ao xerocar as imagens, por exemplo, "acidentes estéticos" aconteciam, rompendo com uma lógica somente narrativa e proporcionando, assim, visualidades não imaginadas. Divertia-me com isso! Tomei ao pé da letra a ideia de brincar, de jogar, de me dispor a aceitar os acasos e o imprevisível. Incorporei variações das imagens e também outros materiais, tais como lápis coloridos, grafite, 
giz de cera, tinta e o próprio desenho do xerox nos tecidos, além de imagens impressas com cor e em preto e branco. Estimulada pelas possibilidades de criação desse procedimento, passei também a experimentar diferentes papeis e tecidos, como suportes e texturas.

Assim, surgiram diversas composições, imagens organizadas e digitalizadas que resultavam em novos textos visuais. Dessa forma, joguei com esses materiais e construí inúmeras visualidades, estabelecendo diferentes relações estéticas, dando visibilidade às imagens e às cenas e, assim, histórias foram se configurando. Nesse aspecto, entendo a ideia heideggeriana (1990) de que entre o artista, a arte e a obra se estabelece uma circularidade, numa circunstância em que não há algo objetificado, pois estão enredados num processo de autocriação. Isto significa que no movimento da criação o artista não tem a autonomia absoluta, pois a materialidade também determina e sugere pensamentos.

\begin{abstract}
A arte encontra ou desvela a verdade do ser porque ela, em obra (realizando) com o artista, "cavoca" mais fundo, dando alguns passos para trás. O jogo jogado entre artista, obra e arte refaz o percurso da própria condição humana, uma vez que a criação artística requer a capacidade de jogar. Isso significa a capacidade de entrega e abertura a um jogo que tem seus próprios modos de ser (pré-ontológico). É ali que a arte pode emergir em obra, configurada em sua materialidade, quando o artista se deixa envolver pelo poético e pela circularidade da criação. Nessa circularidade, ele é atingido pela arte ao mesmo instante em que atinge a materialidade da obra; essa relação, lúdica na essência, é a condição criativa que possibilita que a obra se faça arte e que a arte se faça na obra. Esse jogo é originário da humanidade do homem, pois permite voltar à origem, acedendo à raiz da própria condição humana, em que o brincar e o jogar são dimensões próprias. (JOHANN, 2015, p. 59).
\end{abstract}

Desse modo, compreendo que é a experiência estética quem está no comando e, por isso, vivemos uma experiência como experiência, como quer Gadamer (2010), uma vez que na criação artística acontece um tempo/espaço de intercomplementaridades em que o objeto (a coisa) também nos vem e nos determina. Assim nossa autonomia é relativa e circunscrita no contexto em que algo se dá para nós.

Nesse processo compositivo, busquei a articulação entre as imagens e os elementos visuais, intencionando o poético. Ao mesmo tempo em que não pretendia ficar presa a uma narrativa explícita, também não me satisfazia um mero acaso. 
Queria uma elaboração que articulasse as imagens, as palavras e os diferentes materiais, resultando em uma produção artística que fizesse sentido no emaranhado de pensamentos e memórias que me ocorriam. Percebia que estava envolvida com as narrativas produzidas, embora por vezes confusa, buscando entender os sentidos dos textos visuais: experimentava estados de tensão, excitação e medo que, novamente em Derdyk (2001, p. 15), busco entender, pois ela argumenta que "[...] entre um pensamento e uma ação acontecem tempos, acontecem espaços: intervalos, vãos, breques, lapsos, fusões que no corpo pulsam como células que, involuntariamente, se movimentam em contrações e expansões para sobreviverem $[\ldots] "$.

Figura 8 - Feminina VII

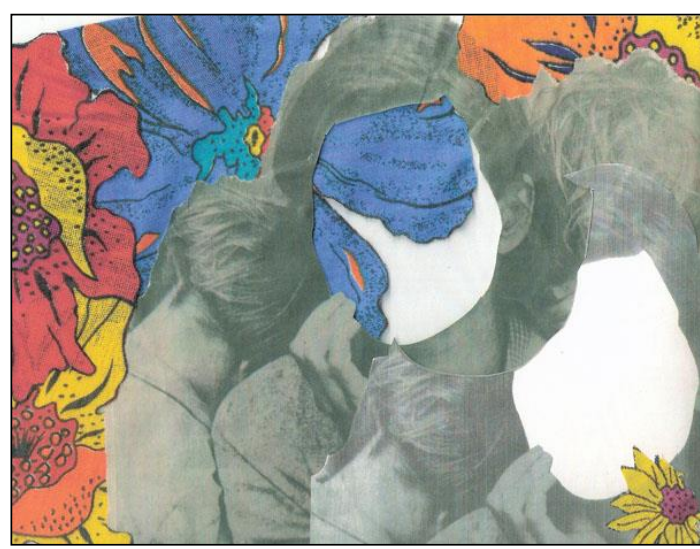

Fonte: acervo da autora.
Figura 9 - Feminina VIII

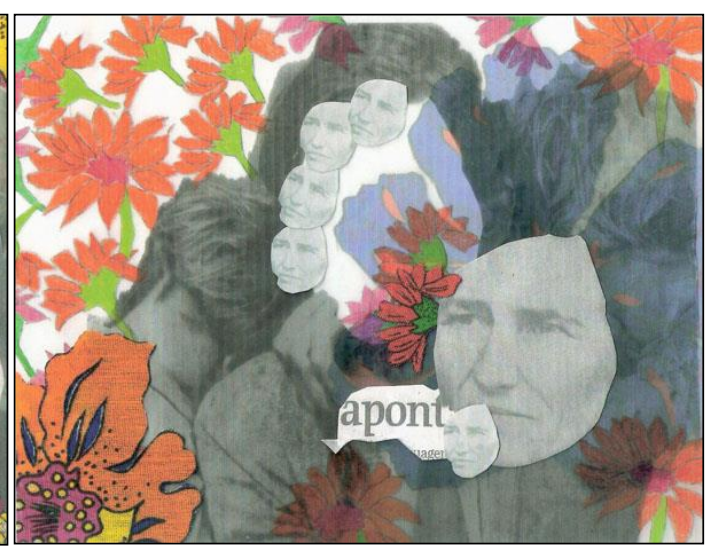

Fonte: acervo da autora.

Com esse trabalho, compreendi melhor o pensamento do professor Marques ${ }^{6}$, quando dizia que é preciso "escrever para pensar", que ideia puxa ideia, que palavra puxa palavra. Ou seja, à medida que fui procurando "coisas" para criar, encontrei nas imagens razões, num primeiro momento subjetivas, que minha história possibilitou. Essas cenas foram construídas pela minha trajetória, tecidas a partir das percepções e lembranças que emergiam daquilo que consegui articular e relacionar. Como catadora, procurei materialidades que dessem conta de exprimir o que pretendia e, por vezes, era o próprio objeto que me permitia pensar.

6 Mário Osório Marques foi meu professor no curso de Mestrado em Educação nas Ciências da UNIJUÍ e, ao nos ajudar a lidar com os dilemas da escrita, afirmava que é preciso escrever para pensar e que escrever é como conversar, basta começar, pois conversa puxa conversa; metáfora que também serve à criação artística. 
Essas cenas fazem parte do imaginário, das memórias que tenho e das que revivi, buscando entender meu trabalho, os textos visuais que e-laborei. Essas imagens são textos sobre os quais produzo pensamento, são tessituras de um exercício criador, ancoradas em memórias que ora reescrevo e reinterpreto. É nessa perspectiva que a arte nos diz algo, solicitando-nos atenção.

\begin{abstract}
A obra de arte que diz algo confronta-nos com nós mesmos. [...] ela anuncia algo que, de acordo com o modo como esse algo é dito, se mostra como uma descoberta, isto é, como o descobrimento de algo encoberto. Nisso repousa aquele encantamento. Nada que conhecemos é "tão verdadeiro, tão assente". Tudo o que conhecemos é aqui excedido. (GADAMER, 2010, p. 7).
\end{abstract}

Ao olhar para o conjunto da pesquisa, ficam, para mim, perguntas, mais do que respostas acerca do que estava fazendo: contando histórias? Resgatando vozes silenciadas? Criando realidades? Reescrevendo minhas lembranças? Materializando ideias para produzir pensamentos?

Essa pesquisa ampliou a compreensão de que "[...] o ato de fazer empurra o corpo para o movimento, impulsiona o desejo, concebe a concretude das ações, agarra e devolve as matérias do mundo ao mundo, encontra outros modos e técnicas de fazer as formas serem" (DERDYK, 2001, p. 20). Nessa pesquisa, produzi três séries, em torno de 100 composições, que organizei em forma de livro de artista (três livros impressos e dois digitalizados) e denominei-os de Tecidos Femininos I, II e III. Neles estão as composições de imagens que se fundem, se intertextualizam, reinventando-se! Faces, flores, palavras hibridizadas, colam-se, descolam-se, fragmentam-se, velam e desvelam memórias femininas. São textos forjados na busca da criação artística, são colagens desejantes do poético, expressões de ideias que se apresentam em meio às lembranças e sentimentos que remetem às histórias femininas que, por vezes, foram dor, suavidade, força e delicadeza. Santas, marias, chitas, personagens de textos visuais que, quando prontos, se constituíram em livros: livros artísticos das memórias femininas. 
Figura 10 - Foto dos livros impressos

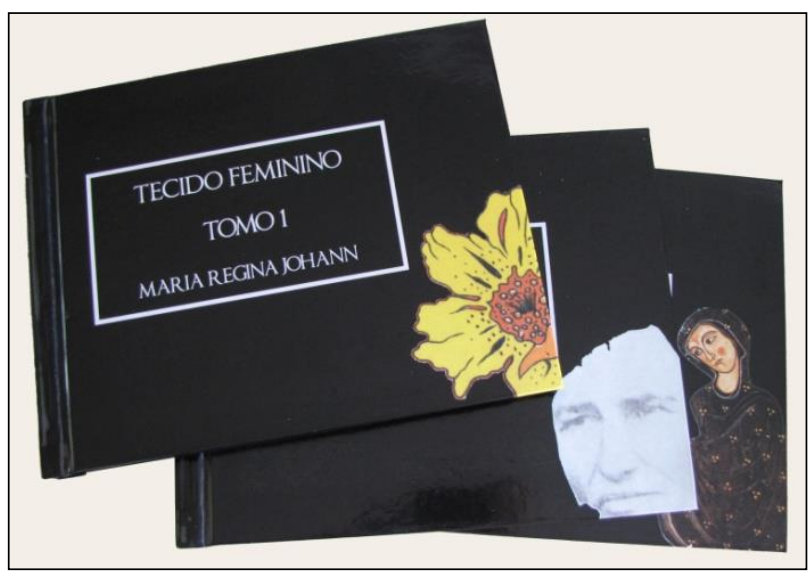

Fonte: acervo da autora.

A partir dessas imagens, pensei minha própria vida, num processo de autoformação e autocriação, uma vez que "[...] as imagens nos constroem como sujeitos num labirinto de teias de significados que se interconectam nas dimensões sociais e simbólicas da cultura" (MARTINS, 2007, p. 33). Mais tarde, compartilhando minha pesquisa com familiares, ouvi que na minha infância gostava de olhar estes tecidos de Chita na casa de comércio de meu pai. As peças de tecidos eram desenroladas para que eu as apreciasse. A partir desse depoimento, minha compreensão se alarga e a ideia de Gadamer (2010) de que, na criação artística, as coisas também nos têm, faz mais sentido para mim, então.

A questão central que evidencio nessa reflexão é o fato de ter me permitido uma questão e suas implicações, colocando-me no movimento de buscar respostas estéticas, constatando (na experiência vivida) que o mundo da obra, ao modo de uma linguagem poética, amplia nosso entender-se no mundo da vida e isso tem um amplo sentido para a autoformação de cada um.

Por fim, reitero que os textos visuais, construídos nessa pesquisa artística, foram tecidos num processo de abertura para as infinitas possibilidades plásticas atravessadas pela vontade de experimentar, manipular, materializar e pensar. O que apresento é artepensamento; ideias e sentimentos materializados a partir de uma experiência artística autocriadora. Esse processo não se encerrou, mas se transformou em uma pesquisa com pintura, na qual manipulo diferentes tecidos, criando ilusões visuais por meio das colagens e das sobreposições de figuras. 


\section{Referências}

DERDYK, Edith. Linha de horizonte: por uma poética do ato criador. São Paulo: Escuta, 2001.

GADAMER, Hans-Georg. Hermenêutica da obra de arte. Seleção e tradução Marco Antonio Casanova. São Paulo: Editora WMF/ Martins Fontes, 2010.

HEIDEGGER, Martin. A origem da obra de arte. Tradução Maria da Conceição Costa. Rio de Janeiro: Edições 70, 1990.

HERNÁNDEZ, Fernando. Catadores da cultura visual: proposta para uma nova narrativa educacional. Porto Alegre: Mediação, 2007.

JOHANN, Maria Regina. Linguagem, arte e educação ético-estética em perspectiva hermenêutica filosófica. Ijuí: UNIJUÍ, 2015. Tese (Doutorado em Educação nas Ciências) - Programa de PósGraduação em Educação nas Ciências, Universidade Regional do Noroeste do Estado do Rio Grande do Sul, ljuí, 2015.

MARQUES, Mário Osório. Escrever é preciso: o princípio da pesquisa. ljuí: Ed. Unijuí, 1998.

MARTINS, Raimundo. A cultura visual e a construção social da arte, da imagem e das práticas do ver. In: OLIVEIRA, Marilda Oliveira de (Org.). Arte, educação e cultura. Santa Maria: Ed. UFSM, 2007. p. 19-40.

PIMENTEL, Airton. Charqueada. Interpretação do Grupo Os Tápes. In: Música popular do Sul, Disco vinil, v. 1, 1975.

A Grande Depressão sob as lentes de Dorothea Lange, $2012 . \quad$ Disponível em:<https://olharconstruido.wordpress.com/2013/05/16/a-grande-depressao-sob-as-lentes-dedorothea-lange/>. Acesso em: 20 de agosto de 2016.

\section{Maria Regina Johann}

Graduada em Educação Artística, com especialização em Metodologia do Ensino de Arte, mestrado e doutorado em Educação nas Ciências pela Universidade Regional do Noroeste do Estado do Rio Grande do Sul - UNIJUI. Professora do Departamento de Humanidades e Educação e coordenadora do Programa de Formação de Professores da UNIJU. Participa do Grupo de Pesquisa Teorias Pedagógicas e Dimensões Éticas e Políticas da Educação, do Grupo Mongaba e do GEPEI tematizando, respectivamente, questões como: linguagem, arte e educação, linguagem e cultura digital na educação escolar e a área da Linguagem no Ensino Médio. É artista visual do grupo ArteSeis Atelier.

E-mail: maria.johann@unijui.edu.br

Currículo: http://lattes.cnpq.br/1342712435989637

Recebido em 31 de agosto de 2016 Aceito em 03 de dezembro de 2016 